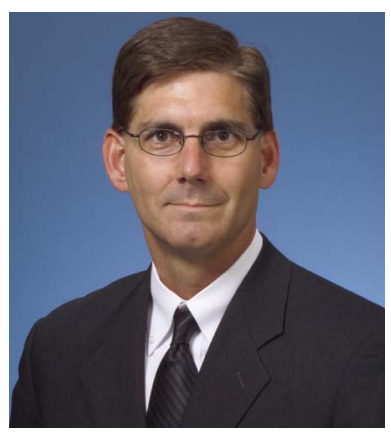

\title{
Relevance and Interest
}

My 25-year-old son rarely listens to me anymore. When I want to talk about religion, the news, politics, current events, or even family matters, his eyes glaze over and I can just tell his mind is wandering through some other time and place. If I want to talk about cars, shooting pool, tattoos, or beer, he perks up and we have a short talk that is both relevant and interesting to him. It's not long before my eyes glaze over and my mind wanders through some other time and place (both relevant and interesting to me).

I mentioned last month that I would be describing some new efforts that we will pursue this year to improve the readership and impact factor of Optical Engineering. Papers accepted by Optical Engineering have to satisfy the basic requirements of significance and originality. In addition, we will be pursuing relevance and interest with the following efforts that will be implemented this year:

1. A new Associate Editor (Eddie Jacobs) will be heading up a student advisory board. The primary reason is to obtain input on how our young authors and readers want their work published and how they want to read new work.

2. We have added three Associate Editors for the three major SPIE conferences. These AEs will keep an eye open at the conference for outstanding papers (and will help recruit them). They will also determine which sessions are hot with standing room only. These sessions may be prime topics for special sections.

3. We will be soliciting for special sections. These sections must be in an area that is relevant and of high interest. I have a goal that by 2011, these special sections will be occurring about every other month. The special section will not replace the normal monthly journal but will be a section in the journal. Please contact me if you have an idea on a high-relevance, high-interest topic.
4. We want to publish tutorial papers and review papers. Again, these are in areas of relevance and high interest. A large number of senior optical engineers are eligible for retirement with significant experience. I would like these people to contribute tutorials and/or review papers for the benefit of our younger scientists and engineers.

5. We will be inviting authors of high-interest proceedings papers to submit an improved manuscript to Optical Engineering. I have asked the Associate Editors to keep their eyes open for outstanding proceedings papers. Also, I have been keeping an eye on the Top 10 Downloads from the SPIE Digital Library and inviting those proceedings that make the list.

These efforts are intended to increase the content of Optical Engineering that is both relevant and interesting. In addition to these efforts, we are monitoring the conference and session attendance (to determine high-interest areas). We are continuing with Don O'Shea's high standards of not publishing the "so what?" or "not wrong" papers (papers that are correct, but do not have much of a contribution). We will also maintain a conservative acceptance rate. Since Optical Engineering is a service journal to the optical engineering community, it is important to provide content that is both relevant and interesting.

There are a few topics that my son and I both find relevant and interesting. He is a diabetic and he became extremely ill in January. His health and well-being are both relevant and of high interest to both of us. When I spent time in the hospital with him, we really connected because of the mutual relevance and interest. He is recovering nicely, but it is only a matter of time before we are back to the small talk.
Ronald G. Driggers

Editor 